\title{
Nanoconfined Synthesis of Nitrogen-rich Metal-free Mesoporous Carbon Nitride Electrocatalyst for the Oxygen Evolution Reaction
}

Md A. Wahab, ${ }^{\text {abd*}}{ }^{\dagger \dagger}$ Jickson Joseph, ${ }^{\text {ac } \Pi}$ Luqman Atanda, ${ }^{\text {ab }}$ Ummul K. Sultana, ${ }^{\text {a }}$ Jorge N. Beltramini, ${ }^{\text {ab }}$ Kostya (Ken) Ostrikov, ${ }^{\text {ac }}$ Geoffrey Will, ${ }^{\text {a }}$ Anthony P. O'Mullane, ${ }^{\mathrm{a}^{*}}$ Ahmed Abdala, ${ }^{\mathrm{d}}$

a School of Chemistry, Physics and Mechanical Engineering, Queensland University of Technology (QUT), Brisbane, QLD 4001, Australia; ${ }^{b}$ Australian Institute of Bioengineering and Nanotechnology, The University of Queensland, St Lucia, QLD 4072, Australia; ' CSIRO-QUT Joint Sustainable Processes and Devices Laboratory, Commonwealth Scientific and Industrial Research Organisation, P.O. Box 218, Lindfield, NSW 2070, Australia; ${ }^{\mathrm{d} C h e m i c a l ~ E n g i n e e r i n g ~ P r o g r a m, ~ T e x a s ~ A \& M ~ U n i v e r s i t y ~ a t ~ Q a t a r, ~ P . O . ~}$ 23874, Doha, Qatar. ${ }^{\dagger}$ Institute of Advanced Study, Chengdu University, Chengdu 610106, Sichuan, China, Corresponding e-mail: m.wahab@qut.edu.au \& mabdul.wahab@outlook.com (orcid.org/0000-0002-53341103); anthony.omullane@qut.edu.au; Пequal contributor for this work.

KEYWORDS. Carbon nitride, electrodes materials, electrochemistry, nanomaterials, oxygen evolution reaction, catalyst, energy materials, water splitting nanomaterials. 


\section{Table and Figure caption}

Table S1. Comparison of carbon nitride-based materials for comparison. We have also compared with g-C3N4 NSs doped with CNT materials to understand where our results stand.

Table S2. EIS fitted parameters of data shown in Figure 6c.

Figure S1. Raman spectrum of mesoporous carbon nitride material

Figure S2. Electrochemical responses of mesoporous carbon nitride nanostructured electrocatalyst: LSV curves of (a) non-templated pure carbon nitride (nTCN) and (b) mesoporous SBA15 silica templated mesoporous carbon nitride (gMesoCN) in $0.1 \mathrm{M} \mathrm{KOH}$ at $10 \mathrm{mVs}^{-1}$.

Figure S3: Tafel plot for gMesoCN recorded in $0.1 \mathrm{M} \mathrm{KOH}$.

Figure S4. Scanning electron microscope (SEM) for various samples.

Figure S5. Equivalent circuit used for data fit, where R1 is solution resistance, C2 is the dielectric capacitance, R2 is the charge transfer resistance, C3 corresponds to the film capacitance and R3 corresponds to the film resistance.

Figure S6: RRDE voltammogram for the reduction of $0.1 \mathrm{mM}$ potassium ferricyanide where ferricyanide is reduced at the disk that results in a disk current and the generated ferrocyanide is oxidised at the ring which results in the ring current. The sweep rate was $10 \mathrm{mV} \mathrm{s}^{-1}$ and the Pt ring was held at a potential of $0.60 \mathrm{~V}$.

Figure S7: RRDE voltammogram of gMesoCN in $1 \mathrm{M} \mathrm{KOH}$ recorded at a sweep rate of 10 mVs- 1 where the Pt ring electrode was held at a potential of $-0.4 \mathrm{~V}$. 


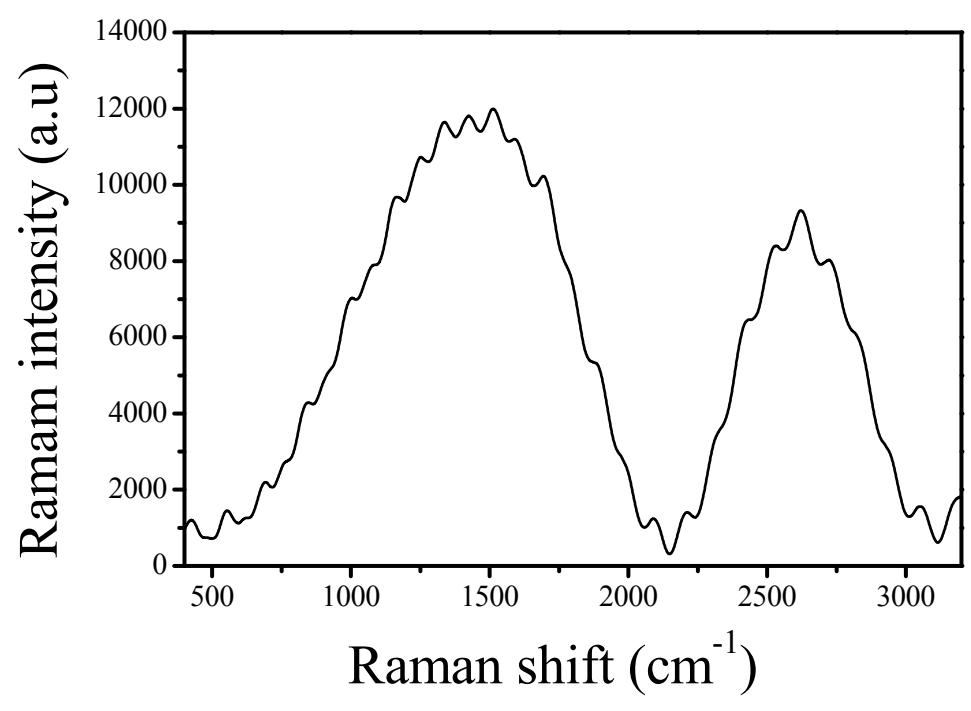

Figure S1. Raman spectrum of mesoporous carbon nitride material. Thermo Fisher Scientific, Madison, WI, USA) equipped with a $780 \mathrm{~nm}$ LASER source for excitation. The spectrum acquisition consisted of 20 accumulations with a total acquisition time of 5 min at a spectral resolution of $4 \mathrm{~cm}^{-1}$ and laser power of $5 \mathrm{~mW}$.

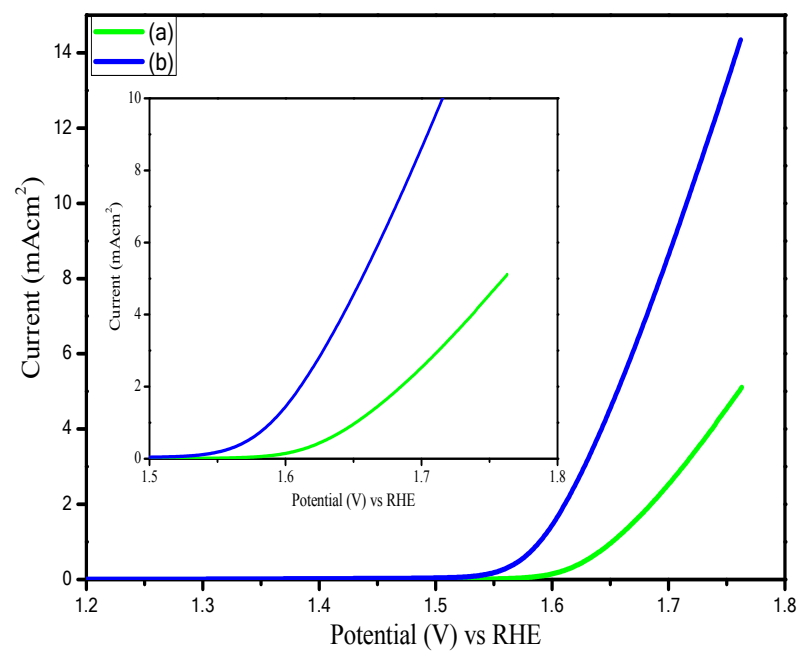

Figure S2. Electrochemical responses of mesoporous carbon nitride nanostructured electrocatalyst: LSV curves of (a) non-templated pure carbon nitride (nTCN) and (b) mesoporous SBA15 silica templated mesoporous carbon nitride $(\mathrm{gMesoCN})$ in $0.1 \mathrm{M} \mathrm{KOH}$ at $10 \mathrm{mVs}^{-1}$. 


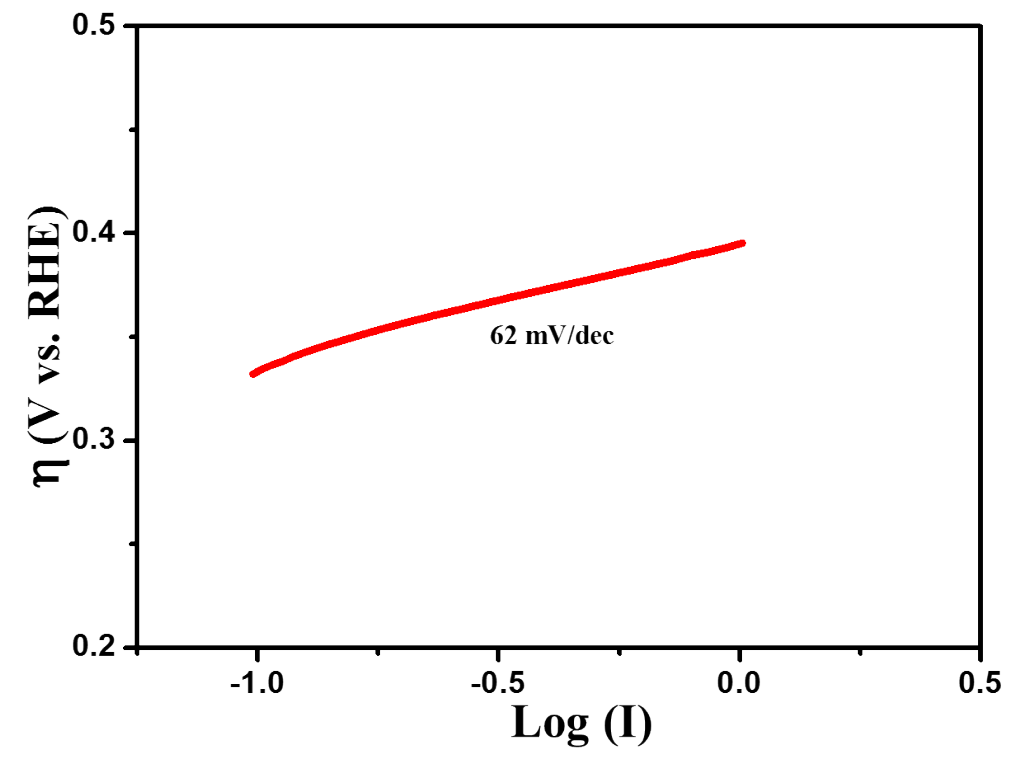

Figure S3: Tafel plot for gMesoCN recorded in $0.1 \mathrm{M} \mathrm{KOH}$.
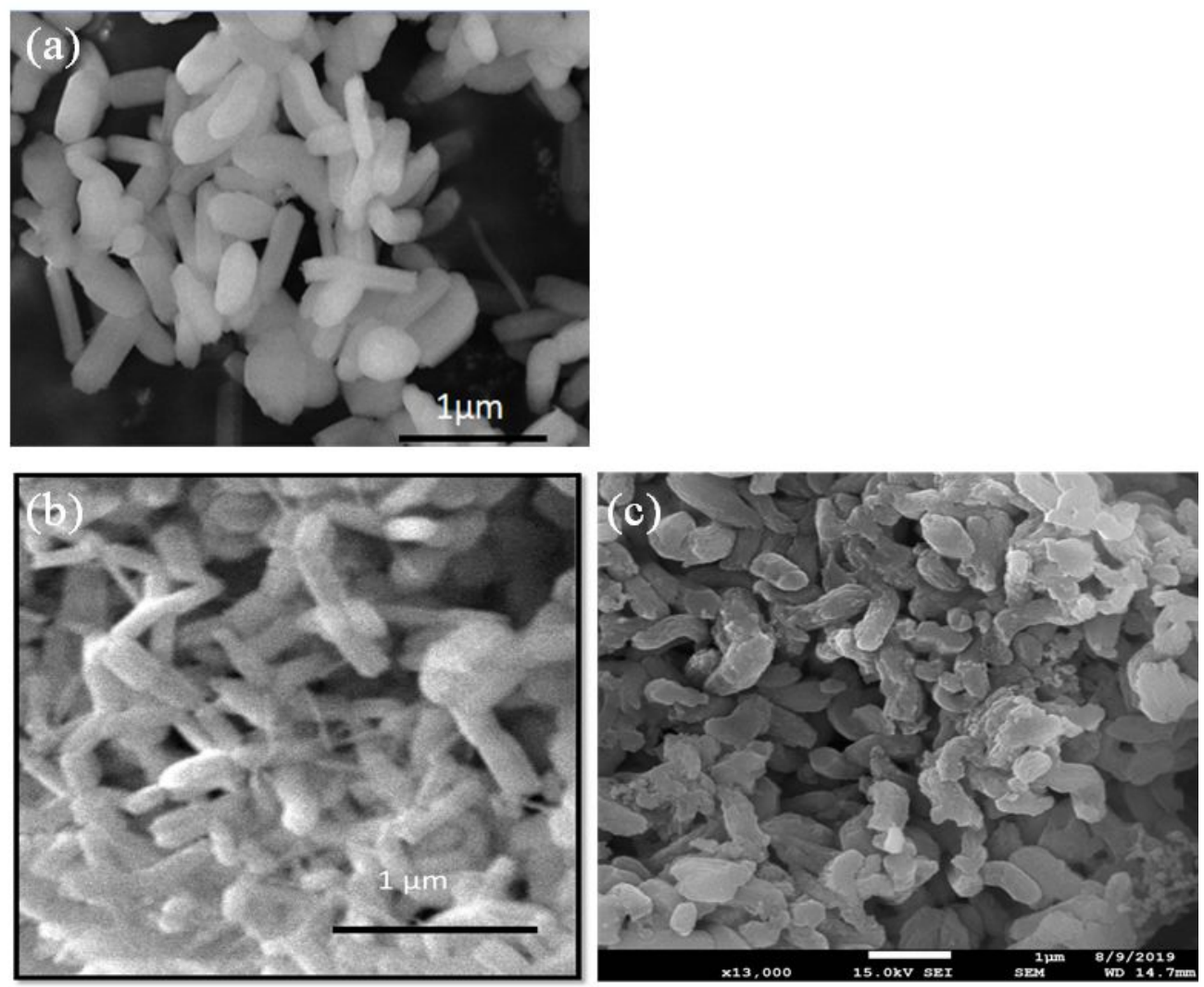

Figure S4. Scanning electron microscope (SEM) for (a) surfactant free-SBA15 silica template, (b) pure gMesoCN sample, and (c) After $24 \mathrm{~h}$ of electrolysis. 
Table S1. Comparison of carbon nitride-based materials for the OER. We have also compared with $\mathrm{g}-\mathrm{C}_{3} \mathrm{~N}_{4} \mathrm{NSs}$ doped with $\mathrm{CNT}$ materials to understand where our results stand.

\begin{tabular}{|c|c|c|c|c|c|}
\hline Catalyst & $\begin{array}{c}\text { Onset } \\
\text { Potential } \\
\text { (V vs } \\
\text { RHE) }\end{array}$ & $\begin{array}{c}\mathrm{V} \text { at } 10 \\
\mathrm{~mA} / \mathrm{cm}^{2} \\
(\mathrm{~V} \text { vs } \\
\mathrm{RHE})\end{array}$ & $\begin{array}{l}\text { Tafel Plot } \\
(\mathrm{mV} / \mathrm{dec})\end{array}$ & Electrolyte/pH & Reference \\
\hline $\begin{array}{c}\text { nTCN (Non- } \\
\text { templated } \\
\text { carbon nitride) }\end{array}$ & 1.55 & 1.647 & 68.9 & $1 \mathrm{M} \mathrm{KOH}$ & \multirow[t]{3}{*}{ This study } \\
\hline $\begin{array}{l}\text { gMesoCN } \\
\text { (SBA15 } \\
\text { templated) }\end{array}$ & 1.514 & 1.606 & 52.4 & $1 \mathrm{M} \mathrm{KOH}$ & \\
\hline $\begin{array}{l}\text { gMesoCN } \\
\text { (SBA15 } \\
\text { templated) }\end{array}$ & 1.545 & 1.71 & 62 & $0.1 \mathrm{M} \mathrm{KOH}$ & \\
\hline $\begin{array}{l}\text { Bulk g-CN from } \\
\text { melamine } \\
\text { source }\end{array}$ & 1.70 & 1.91 & - & $\begin{array}{c}\mathrm{pH} 14 \text { in } \\
\mathrm{KOH}\end{array}$ & \multirow[t]{2}{*}{53} \\
\hline $\begin{array}{c}\mathrm{g}-\mathrm{CN} \\
\text { nanostructures } \\
\text { from melamine } \\
\text { source } \\
\end{array}$ & 1.55 & 1.71 & 120 & $\begin{array}{c}\mathrm{pH} 14 \text { in } \\
\mathrm{KOH}\end{array}$ & \\
\hline $\begin{array}{c}\mathrm{g}-\mathrm{C}_{3} \mathrm{~N}_{4} \\
\text { nanosheet from } \\
\text { melamine }\end{array}$ & 1.764 & 1.96 & 120.9 & \multirow[t]{2}{*}{$0.1 \mathrm{M} \mathrm{KOH}$} & \multirow[t]{2}{*}{52} \\
\hline $\begin{array}{c}\text { g- } \\
\mathrm{C}_{3} \mathrm{~N}_{4} / \text { graphene }\end{array}$ & 1.614 & 1.98 & 68.5 & & \\
\hline $\mathrm{g}-\mathrm{C}_{3} \mathrm{~N}_{4}$ & 1.65 & $\begin{array}{c}\text { Not } \\
\text { reportable } \\
\text { value }\end{array}$ & 136.2 & \multirow[t]{2}{*}{$0.1 \mathrm{M} \mathrm{KOH}$} & \multirow[t]{2}{*}{36} \\
\hline $\begin{array}{l}\text { Hybrid structure } \\
\text { from } \mathrm{Ti}_{3} \mathrm{C}_{2}\end{array}$ & 1.58 & 1.66 & 119.7 & & \\
\hline $\mathrm{g}-\mathrm{C}_{3} \mathrm{~N}_{4} \mathrm{NSs}$ & Negligible & Negligible & $\begin{array}{c}\text { Not } \\
\text { reported }\end{array}$ & $0.1 \mathrm{M} \mathrm{KOH}$ & 49 \\
\hline $\begin{array}{c}\mathrm{g}-\mathrm{C}_{3} \mathrm{~N}_{4} \mathrm{NSs} \\
\text { doped with } \\
\mathrm{CNT} \\
\end{array}$ & 1.53 & 1.60 & 83 & & 49 \\
\hline $\begin{array}{c}\text { N-doped } \\
\text { mesoporous } \\
\text { carbon } \\
\text { nanosheet/CNT) } \\
\text { hybrids } \\
\end{array}$ & 1.50 & 1.55 & 55 & $0.1 \mathrm{M} \mathrm{KOH}$ & 77 \\
\hline $\begin{array}{c}\mathrm{N} \text {-doped } \\
\text { mesoporous }\end{array}$ & 1.53 & 1.632 & 67 & $0.1 \mathrm{M} \mathrm{KOH}$ & 73 \\
\hline
\end{tabular}


Table S2. EIS fitted parameters of data shown in Figure $6 \mathrm{c}$.

\begin{tabular}{|c|c|c|c|c|c|}
\hline & $\mathbf{R 1}=\mathbf{R}_{\mathbf{s}}(\boldsymbol{\Omega})$ & $\mathbf{R 2}=\mathbf{R}_{\text {ct }}(\boldsymbol{\Omega})$ & $\begin{array}{c}\mathbf{C 2}=\mathbf{C}_{\text {dl }} \\
(\boldsymbol{\mu} \mathbf{F})\end{array}$ & $\begin{array}{c}\mathbf{C 3}=\mathbf{C}_{\text {film }} \\
(\boldsymbol{\mu} \mathbf{F})\end{array}$ & $\begin{array}{c}\mathbf{R 3}=\mathbf{R}_{\text {film }} \\
(\boldsymbol{\Omega})\end{array}$ \\
\hline nTCN & 2.116 & 11.5 & 554.6 & 364.9 & 1.28 \\
\hline gMesoCN & 1.379 & 4.47 & 2158 & 1084 & 0.39 \\
\hline
\end{tabular}

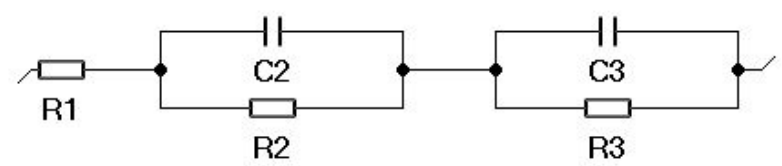

Figure S5. Equivalent circuit used for data fit, where R1 is solution resistance, $\mathrm{C} 2$ is the dielectric capacitance, R2 is the charge transfer resistance, C3 corresponds to the film capacitance and R3 corresponds to the film resistance.

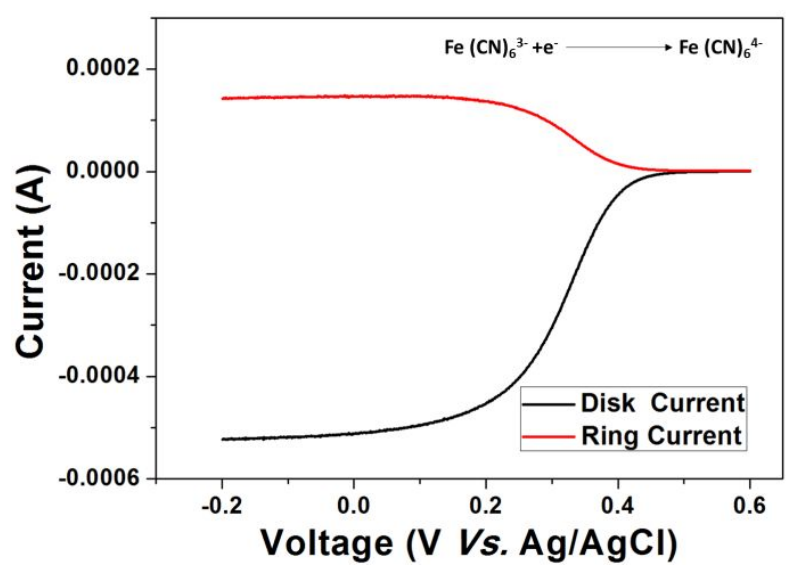

Figure S6: RRDE voltammogram for the reduction of $0.1 \mathrm{mM}$ potassium ferricyanide where ferricyanide is reduced at the disk that results in a disk current and the generated ferrocyanide is oxidised at the ring which results in the ring current. The sweep rate was $10 \mathrm{mV} \mathrm{s}^{-1}$ and the Pt ring was held at a potential of $0.60 \mathrm{~V}$.

Collection efficiency of the Ring electrode (Ferrocyanide) $=\mathrm{I}_{\text {ring }} / \mathrm{I}_{\text {disk }}=27.25 \%$ 


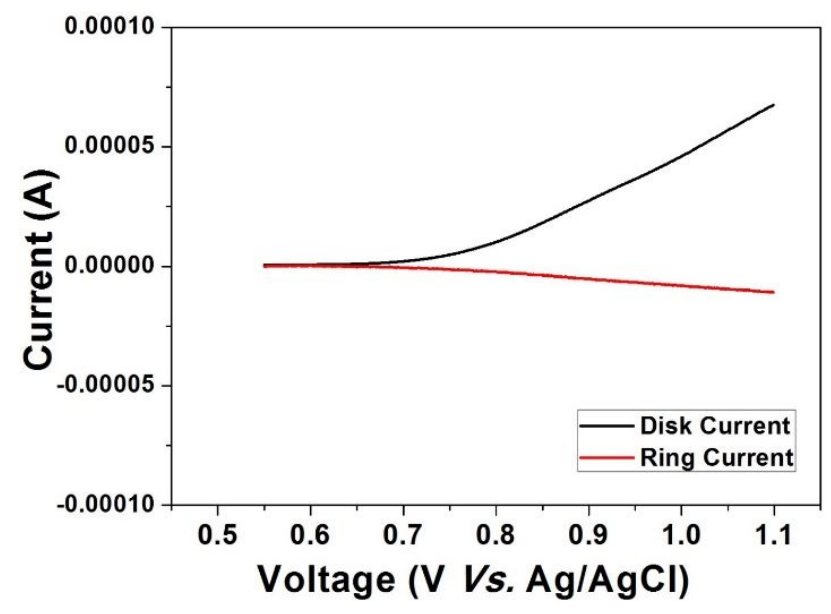

Figure S7: RRDE voltammogram of gMesoCN in $1 \mathrm{M} \mathrm{KOH}$ recorded at a sweep rate of 10 mVs- 1 where the Pt ring electrode was held at a potential of $-0.4 \mathrm{~V}$.

Faradaic efficiency $=\mathrm{I}_{\text {ring }} /\left(\mathrm{I}_{\text {disk }} \mathrm{x}\right.$ Disk efficiency $)$

Faradaic efficiency $=87 \%$ 